\title{
PerCursos
}

\section{Democracia colapsada e alternativas às utopias do capitalismo pandêmico}

\section{Resumo}

Sendo a democracia do capitalismo limitada em sua extensão para a manutenção do sistema que oprime e rompe com o metabolismo do planeta, alternativas sistêmicas devem ser necessariamente anticapitalistas. A partir da experiência de acirramento do capitalismo durante a pandemia de Covid-19, mediada pelo aumento da digitalização e pela tecnologia a serviço de outras formas de exploração, importa reiterar seu caráter distópico - confrontando-o com sua natureza expropriatória. Conformada às entranhas do capitalismo, a tecnologia não proverá outro resultado senão sua reprodução, pois que concebida para operar dentro da racionalidade tecnológica desse sistema nutridor do pensamento unidimensional. Em face desse cenário, o Confederalismo Democrático de Rojava guarda potencialidade para um projeto ecossocialista contrahegemônico de questionamento às bases do sistema por meio de participação popular e ecologia. Considerando que o ecossocialismo associa a crítica marxista do capital e a alternativa socialista com a crítica ecológica do produtivismo, trata-se de modelo de combate à raiz das agruras do sistema econômico vigente.

Palavras-chave: Capitalismo. Distopias. Democracias Populares.
Raquel Requena Rachid Doutoranda em Mudança Social e Participação Política pela Escola de Artes, Ciências e Humanidades da Universidade de São Paulo USP. Pesquisadora da Rede de Pesquisa Solidária - RPS e do Laboratório de Políticas Públicas e Internet - LAPIN. Brasil raquel.rachid@usp.br

\section{Para citar este artigo:}

RACHID, Raquel Requena. Democracia colapsada e alternativas às utopias do capitalismo pandêmico.

PerCursos, Florianópolis, v. 21, n.47, p. 31 - 56, set./dez. 2020. 


\title{
Collapsed democracy and alternatives for the pandemic capitalism utopia
}

\begin{abstract}
Since the democracy of capitalism is limited in its extent to the maintenance of the system that oppresses and breaks the planet's metabolism, systemic alternatives must necessarily be anti-capitalist. Based on the experience of worsening capitalism during the Covid-19 pandemic, mediated by the increase in digitalization and technology at the service of other forms of exploitation, it is important to reiterate its dystopian character - confronting it with its expropriatory nature. Conformed to the bowels of capitalism, technology will provide no other result than its reproduction since it was conceived to operate within the technological rationality of this one-dimensional thought-nourishing system. In the face of this scenario, Rojava's Democratic Confederalism holds the potential for a counter-hegemonic eco-socialist project of questioning the system's bases through popular participation and ecology. Considering that eco-socialism associates the Marxist critique of capital and the socialist alternative with the ecological critique of productivism, it is a model for fighting the root of the hardships of the current economic system.
\end{abstract}

Keywords: Capitalism. Dystopias. Popular democracies. 


\section{Introdução}

Considerando-se a utopia um fenômeno de idealização da sociedade perfeita pela ênfase em condições que possibilitariam a vida abundante e de qualidade, com caráter confiante e otimista no futuro, esta é confrontada com a antiutopia (distopia) reveladora das contradições que impossibilitam sua fruição. A distopia revela os traços míopes da visão utópica, suas distorções são expostas de forma crítica a partir de tendências que remetem à realidade.

Enquanto o sistema capitalista, que nunca escondeu suas agruras, não as expunha da maneira crua que escancara durante a experiência da pandemia - especialmente em países do sul global como o Brasil -, a defesa da não interferência do Estado na economia era diluída frente a um quadro de natureza múltipla que inibia a divulgação da mais natural sustentação desse sistema nas relações de concepção dos Estados nacionais. Era, então, possível a camuflagem da operação de sobrevivência do sistema econômico.

Em virtude da naturalidade cada vez mais notória de interação entre os setores público e privado (ESTEVE, 2017, p. 119), a dependência do Estado com relação ao poder econômico e as bases (MASCARO, 2013, p. 49) que o primeiro estruturou para que o capitalismo fluísse, tornaram-se cada vez menos aparentes. Trata-se de um cenário explorado por Apple, conforme o seguinte excerto:

Enquanto o liberalismo clássico representa uma concepção negativa do poder do Estado, no sentido de que o indivíduo era tido como objeto a ser libertado das suas intervenções, o neoliberalismo acabou por representar uma concepção positiva do papel do Estado, ao criar mercado apropriado, pois fornece as condições, leis e instituições necessárias a seu funcionamento. (APPLE, 2005, p. 37)

O advento do novo coronavírus projeta holofotes sobre essa relação a partir da necessidade de intervenção dos cofres públicos globais quanto ao salvamento de setores das economias que tiveram declínio notório de sua atuação, bem como garantia de condições mínimas às populações locais. 
O engodo do livre mercado já havia sido desmascarado em eventos como o da crise de 2008. Ao ser novamente revelado, conta com um momento em que a economia digital ganha contornos necessários por viabilizar soluções em meio ao devido distanciamento social'1, o que promete um cenário de eternização das Big Tech e novas soluções - mesmo que prescindindo de discussões com a sociedade, como subterfúgio de combate ao vírus².

Obviamente, as medidas de distanciamento social dependem muito das possibilidades materiais para seu gozo; parte considerável das cidades brasileiras não pôde usufruir desse expediente ${ }^{3}$. O Brasil, marcado por disparidades que foram acirradas, enfrenta (para além da pandemia) um governo federal comprometido com o genocídio4; ao menosprezar o potencial lesivo do vírus e retardar a adoção de medidas de socorro à população, bem como sua efetivação, externa uma guinada autoritária e de cunho fascista5. Então, e mais do que nunca, existe a necessidade premente de se conceituar o tipo de democracia que convive com o capitalismo:

\footnotetext{
${ }^{1}$ A partir de um levantamento sobre a maximização da digitalização e os efeitos da pandemia do COVID-19 quanto à transformação digital de pequenos negócios, pesquisadores da Universidade de Pernambuco indicam que "negócios que estavam num estágio avançado de transformação digital puderam se adaptar melhor a essas novas condições, enquanto que negócios tradicionais se viram forçados a se adaptar abruptamente" (GUIMARÃES JÚNIOR et al., 2020, p. 4).

${ }^{2}$ Mencionando a suposta solução trazida pela tecnologia ao momento que vivemos, Mark Andrejevic e Neil Selwyn (2020) comentam de forma crítica a ideia espraiada de que os maiores problemas poderiam ser superados com os aparelhos, softwares e códigos corretos. Indicam que a COVID-19 estaria mostrando como os indivíduos estão sujeitos a sistemas de monitoramento, comentando casos como o da Coréia do Sul, de Taiwan e da China - país que impôs o uso de um aplicativo produzido por uma afiliada da gigante Alibaba como medida governamental de contenção ao vírus.

3 Em seu $17^{\circ}$ Boletim, a Rede de Pesquisa Solidária (CASTELLO; VIEIRA; PICANÇO, 2020) indica o enfrentamento das necessidades materiais (fome, acesso a trabalho e acesso ao auxílio emergencial - por exemplo) causadas pela pandemia como o principal problema que assola as comunidades de oito regiões metropolitanas do Brasil; os dados foram coletados por meio de entrevistas com 75 líderes comunitários.

${ }^{4}$ Para além da edição de uma série de medidas provisórias que, dentre outros aspectos, precarizaram as relações de trabalho (BRASIL, 2020a) e tardaram tanto no suporte de populações mais vulneráveis (como as comunidades indígenas e quilombolas) quanto na concessão de auxílio emergencial (BRASIL, 2020b), é imprescindível retomar falas de menosprezo à gravidade da pandemia do COVID-19 pelo presidente da república; "gripezinha", "fantasia" e "histeria" foram algumas das palavras utilizadas por Bolsonaro, que - ao invés de prover condução nacional mínima para o enfrentamento da calamidade - não deixou de alimentar instabilidades políticas. Não se pode concluir de outra forma senão pelo desprezo por vidas de milhares de brasileiros, ceifadas em meio à maior crise global do nosso tempo.

${ }^{5}$ Ao conceituar o fascismo, Leandro Konder (2009, p. 53) indica exprimir-se através de uma política favorável à crescente concentração do capital, sendo um movimento político de cunho social conservador, o qual se disfarça sob uma máscara "modernizadora"; acresce que o fascismo é um movimento chauvinista, antiliberal, antidemocrático, antissocialista e antioperário cujo crescimento em
} 
A democracia "formal" e a identificação da democracia com o liberalismo seriam impossíveis na prática e literalmente impensáveis na teoria em outro contexto que não fosse o contexto tão específico das relações sociais do capitalismo. Essas relações sociais possuem tanto uma democracia avançada quanto estritamente limitada, e o maior desafio do capitalismo seria a extensão da democracia para além de limites estreitamente circunscritos. É nesse ponto que "democracia" torna-se sinônimo discutível de socialismo. (WOOD, 1995, p. 15)

Tem-se, assim, que na democracia do capitalismo a desigualdade socioeconômica e a exploração de classe coexistem com a igualdade civil, o que caracteriza sua formalidade. Nesse contexto, e partindo do pressuposto de que esse sistema forja indivíduos aquiescentes com suas características, a essência da condição humana é desafiada e explorada ao limite - até mesmo no que diz respeito às horas de sono:

O sono é uma afirmação irracional e intolerável de que não é irrestrita a compatibilidade de seres vivos com as forças supostamente irresistíveis da modernização. Um dos conhecidos truísmos do pensamento crítico contemporâneo é que não existem características naturais inalteráveis nem mesmo a morte, segundo aqueles que preveem que em breve estaremos transferindo os dados de nossa mente para uma forma digital de imortalidade. Acreditar que existam traços essenciais que distinguem seres vivos de máquinas é, dizem-nos críticos célebres, ingênuo e delirante. Por que alguém protestaria, pode-se argumentar, se novas drogas nos permitissem trabalhar por cem horas seguidas? Períodos de sono mais flexíveis e reduzidos não possibilitariam uma liberdade pessoal maior e a organização da própria vida de acordo com necessidades e desejos individuais? Menos sono não permitiria mais oportunidades de "viver a vida ao máximo"? [...] No paradigma neoliberal globalista, dormir, é acima de tudo, para os fracos. (CRARY, 2016, p. 23)

A ruptura metabólica (FOSTER, 1999) produzida pelo capitalismo e pela infraestrutura tecnológica de sua faceta industrial dialogam com a impossibilidade de se

um país pressupõe condições históricas especiais de enfraquecimento das forças antifascistas junto às massas. Em reforço a essa concepção, no contexto atual brasileiro vê-se a clara estigmatização e depreciação de alguns grupos (mulheres, indígenas, homossexuais, negros, comunistas, ambientalistas, defensores de direitos humanos, pessoas não defensoras de valores cristãos) em momentos de manifestações autoritárias como a reunião ministerial da presidência da república de 22 de abril de 2020 divulgada em razão de representar o interesse de Bolsonaro em proteger sua família, intervindo na Polícia Federal. 
estender por mais tempo esse modo de produção, mesmo que sua máquina insista em não cessar. A ideia de ruptura metabólica reflete a dinâmica truncada entre as relações humanas com a natureza, indicando que seu desequilíbrio pode levar à extinção da vida na terra.

Como o capitalismo promove uma mistificação da economia a fim de que o ser consumidor reste hipnotizado sem reparar nos limites que nos cercam, reforça a ilusão da necessidade de o ritmo de produção ser mantido para que seu equivalente em utopia do desenvolvimento seja nutrido; mesmo que o resultado da produção seja ineficiente do ponto de vista da manutenção de um ambiente amplamente equilibrado. O fato de gerar acumulação para um grupo privilegiado, compensa a mistificação.

Ao mesmo tempo em que promove a cooptação de pautas ambientais (ESTEVE, 2017, p. 176), o capitalismo não pode desmobilizar sua essência geradora de lucro, o que impossibilita o questionamento da lógica do sistema. É nessa dinâmica de desrespeito reiterado a limites (sejam da natureza, do trabalho, da saúde) que a pandemia vivida mundialmente possui suas origens.

COVID-19 é uma pandemia do neoliberalismo, um produto dessa fase neoliberal globalizada do capitalismo. O capitalismo, impulsionado pela globalização neoliberal, estendeu seu manto sobre todo o planeta. As cadeias produtivas globais, que são estabelecidas para que as corporações aumentem seus lucros, tornam cada país vulnerável à menor crise, e a hipermobilidade que as sustenta eliminou qualquer mecanismo de segurança sanitária e ecológica. Uma relação predatória com a natureza, baseada no uso de combustíveis fósseis e na grande agricultura capitalista, com seus desertos verdes, destrói tanto o equilíbrio dos ciclos fundamentais do sistema terrestre (carbono, água, nitrogênio) quanto a relação dos seres humanos com a biosfera, com a teia da vida da qual somos apenas parte. É um modelo insustentável, que visa o crescimento infinito em um planeta finito, que ultrapassa todos os limites da Terra, criando uma alienação ecológica e uma demanda de consumo incompatível com o uso racional de bens comuns. (COMUNA, 2020) 
Nildo Viana (2020) comenta sobre a produção capitalista de pandemias, ressaltando uma mundialização - antes inexistente - de calamidades tanto pela dependência das intensas relações internacionais promovida pela divisão internacional do trabalho e pelo fluxo internacional de pessoas ${ }^{6}$ típicos do capitalismo tardio ${ }^{7}$, quanto em razão das mudanças ambientais e climáticas que geram a emersão de diversos vírus. A ocorrência do novo coronavírus, imediatamente mais perceptível do que suas causas, possui conexão com a reprodução do capitalismo - que, por sua vez, não possui a mesma capacidade de contenção dos efeitos gerados por crises da monta da pandemia do COVID-19.

A industrialização pautada no uso de combustíveis fósseis e no hiperconsumo, com larga emissão de gases de efeito estufa, conduziu a uma excessiva devastação ambiental sob o argumento de progresso e crescimento econômico sem limites. Aliada a isso, a visão da natureza como recurso e objeto de apropriação, domínio e transformação, com base na racionalidade antropocêntrica utilitarista, deu causa a uma radical crise ecológica na atualidade. Exacerbando essa crise, o desmedido aumento demográfico e a crescente urbanização não planejada, predatória e desmedida, transformaram os centros urbanos e seus arredores em nichos de desigualdades, vulnerabilidades e poluição difusa. Para além da destruição da Natureza nas cidades, o campo também sofreu mudanças, com a mecanização da agricultura e com a maior demanda por alimentos. Uso insustentável do solo, perda de biodiversidade e desmatamento, assim, tomaram o lugar da agricultura familiar e da pequena propriedade, trazendo novos elementos para a crise ecológica. A mudança climática demostra cientificamente que se ultrapassou o limite planetário. [...] Sem essa relação harmônica e interdependente com a natureza, estaremos fadados ao extermínio, cometendo um verdadeiro ecocídio. [...] A desestabilização dos ecossistemas naturais tornou emergente o risco de doenças e o surgimento da Covid-19, vez que espécies selvagens perderam seu habitat natural e passaram a viver em ambientes urbanos ou convivendo com espécies já domesticadas, sendo objeto de caça, comércio e manipulação, proximidade espacial que propicia a evolução de patógenos. Assim, na condição de pandemia de saúde global, a Covid-19 lança luz sobre a exploração animal, a relação de objetificação entre ser humano e natureza e a necessidade de estabelecer um ambiente

\footnotetext{
${ }^{6}$ Trata-se de referência ao trânsito facilitado de doenças virais em razão da internacionalização das relações econômicas e sociais.

7 A expressão "capitalismo tardio" refere-se ao modelo avançado das forças produtivas no capitalismo, sistema totalizante que define a sociedade em suas relações de produção e cujo desenvolvimento teria alcançado expansão singular (ADORNO, 1986).
} 
compartilhado e harmônico com os outros seres vivos. (LEITE; BECHHAUSER; BROETTO, 2020)

No estágio atual do capitalismo, de busca por uma noção de progresso lastreada no crescimento econômico, é sempre provável que o artifício da inovação a todo custo (ROSO, 2004, p. 73) e sua defesa sem reservas ignore limites ou perdas; e se solidifique como necessidade inquestionável, reforçando desigualdades. Em uma realidade econômica que não pode parar (de produzir, de inovar), mesmo que isso signifique a morte de uma parcela considerável da população, importa destacar algumas palavras de Herbert Marcuse, em sua obra A Ideologia da Sociedade Industrial:

A tecnologia serve para instituir formas novas, mais eficazes e mais agradáveis de controle social e coesão social [...]. Em face das particularidades totalitárias dessa sociedade, a noção de neutralidade da tecnologia não mais pode ser sustentada. A tecnologia não pode, como tal, ser isolada do uso que lhe é dado; a sociedade tecnológica é um sistema de dominação que já opera no conceito e na elaboração das técnicas. (MARCUSE, 1973, p. 19)

Se as relações sociais do capitalismo estão imbricadas na tecnologia, a representação coletiva da ética da inovação fica a cargo dos interesses e das bases do sistema econômico, que pouco (ou quase nenhum) compromisso têm com as mazelas sociais - uma vez que delas sobrevive (OLIVEIRA, 2003). Trata-se, em conclusão, de atribuir à ética do capital tonalidades de ética coletiva, o que reforça uma confusão não somente terminológica, mas amplamente conceitual.

Cumpre, então, pontuar uma questão que perpassa este trabalho: as “contradições que existem no conceito de progresso - como utilizado para justificar o discurso hegemônico da acumulação" (DUPAS, 2012, p. 27). Nesse cenário de inovação obrigatória, o questionamento às percepções e modificações metabólicas é prejudicado.

O aceno ao futuro pela percepção das inovações como necessárias é utilizado como reforço à utopia do capital na condição de solucionador dos problemas dessa era, 
para a consolidação de novidades que todos os dias precisam se superar. Em anos de repetição desse mantra, o Brasil confere naturalidade à sedimentação da ética da inovação, de um progresso que sacrifica as terras indígenas para que o agronegócio se estabeleça e que expropria o trabalho através do eufemismo da flexibilização das normas trabalhistas.

Em razão da sedimentação de um estado de desigualdades crítico e do desprezo pelos direitos sociais, viu-se a consolidação do modelo de estado da segurança policialesca, de repressão e de reforço à política de encarceramento, para ao menos cegar quanto à real causa das mazelas geradas por escolhas políticas sectárias (SERRES, 2011, p. 85).

Trata-se de uma questão que - não exageradamente - remonta, nas últimas décadas, às disputas em torno do direito à verdade e da justiça de transição após o Golpe de 1964, inclusive. Para além de estruturas institucionais ainda ligadas aos descalabros do passado e ao golpe parlamentar sofrido por Dilma Rousseff, mais recentemente (ambos atrelados à manutenção da ordem política de privilégios), importa ressaltar um histórico sensível no campo da contenção dos gastos sociais como mecanismo debilitador da máquina pública, que corrobora a ética da inovação.

Um cenário organizado para a franca dependência do mercado global, cujo fortalecimento trama também contra a sustentação do indivíduo e a instância da ética individual ${ }^{8}$, para dele se apropriar como sua extensão máxima de alcance - em processo de psicotização já descrito por Dufour:

Como pensar que o neoliberalismo, que destrói as instâncias coletivas, possa deixar intacta a forma sujeito, herdeira de um longo processo histórico, filosófico e teológico-político de individuação? [...] Do lado da consciência reflexiva (processos ditos secundários), o neoliberalismo quer absolutamente acabar com o sujeito crítico, cujo tempo mais forte é constituído pelo kantismo. E do lado do inconsciente (processos ditos primários) o neoliberalismo não tem mais o que fazer com o velho sujeito herdado da modernidade, exposto por Freud, classicamente neurótico e

\footnotetext{
${ }^{8} \mathrm{~A}$ ética individual cindida no percurso de concretização da máxima: "o interesse do mais forte travestido de interesse comum." (GROS, 2019, p. 202).
} 
assaltado pela culpabilidade. Ao invés desse sujeito duplamente determinado, ele quer dispor de um sujeito acrítico e, tanto quanto possível, psicotizante. Isto é, um sujeito disponível para todas as conexões, um sujeito incerto, indefinidamente aberto aos fluxos de mercado e comunicacionais, uma carência permanente de mercadorias para consumir. (DUFOUR, 2005, p. 117)

Esse cenário social esgarçado e estarrecedor deve mobilizar alternativas à utopia de que o capitalismo se regeneraria a partir da pandemia, pois se preocuparia em ser mais sustentável. É tempo de considerar que não há mais condições de coexistência com o capitalismo, que por essência não possui limites aptos a qualquer concepção de sustentabilidade, haja vista a mercantilização que impõe a todas as instâncias da vida.

\section{Os percalços do Capitalismo da Pandemia e o "Mundo Novo"}

O mesmo capitalismo, com contradições evidenciadas pelo advento da pandemia, lança mão de supostas novidades como forma de estabilização do revés gerado pelas próprias estruturas desse sistema econômico, oferecendo um “novo normal”.

Para que as atividades motrizes do sistema não sofressem ruptura, técnicas inovadoras foram utilizadas em larga escala. Não se pode desprezar a amplitude da adoção de mecanismos de trabalho remoto, de contact tracing, de ensino a distância, de entrega em domicílio; trata-se da imposição de alternativas permeadas por tecnologia que garantiriam o distanciamento social.

Antes que se parta à análise das incongruências que perpassam o uso de tecnologias a serviço da manutenção do capitalismo, é importante reiterar a menção à parcela da população que não teve condições de fruir do próprio distanciamento social em razão de condições materiais desfavoráveis, as quais relegaram essa massa de precarizados e despossuídos à exposição ao vírus. No caso brasileiro, importa a remissão a episódios sintomáticos envolvendo trabalhadores e trabalhadoras informais sem acesso ao auxílio emergencial ${ }^{9}$; pessoas em situação de rua não amparadas por políticas

\footnotetext{
9 Trata-se de valor módico, ainda que acima das primeiras intenções do governo federal, que tanto atrasou
} 
emergenciais de socorro; profissionais da saúde da linha de frente, os quais possuíam condições de trabalho já comprometidas antes da pandemia, tendo sido expostos inclusive à falta de equipamentos de proteção adequados.

Uma série de medidas extraordinárias mudaram a rotina de boa parte das pessoas - indivíduos que tiveram sua carga de trabalho multiplicada e conciliada com o uso irrefreado de aparelhos e ferramentas de comunicação, os quais acirraram jornadas, elevando tanto a ansiedade pela manutenção do emprego quanto pela ausência de tempo ou espaço de sossego frente ao acionamento constante ou à intensidade da rotina laboral (UCHÔA, 2020).

Muitos aplicativos foram lançados com funções que prometiam facilidades aos usuários, no que diz respeito à obtenção de informações sobre prevenção ao COVID-19 ou outras matérias relacionadas ao combate à pandemia. Nesse sentido, o que mostra a pesquisa (SHARMA; BASHIR, 2020) conduzida por pesquisadores da Universidade de Illinois, ao analisar 50 aplicativos relacionados ao tema e disponíveis na Google Play, é que houve extrapolação no que diz respeito à finalidade do processamento de dados pessoais de usuários. Dos aplicativos avaliados, 30 requeriam permissão para inúmeros tipos de acesso (contatos, fotos, galeria, localização, câmera, informações de chamada, conexão de wifi, microfone, configurações do celular, dentre outros) desnecessários ao propósito desempenhado pela aplicação, o que demonstra clara violação à privacidade e à proteção de dados pessoais.

Somam-se ao tema os mecanismos desenvolvidos em termos de contact-tracing, os quais foram amplamente adotados por governos para medição da taxa de distanciamento social, sendo em alguns casos até mesmo utilizados para comunicações a usuários que haviam entrado em contato com um potencial infectado. Trata-se de temática também sensível, uma vez que dados anonimizados são sujeitos à desanonimização eventual, conforme mostrou a reportagem do The Intercept, após a desanonimização dos dados de duas pessoas físicas que figuravam em uma lista vendida 
pela maior operadora de celular do Brasil a um ente federativo (DIAS, 2020). Nunca se pode subestimar o capitalismo de vigilância:

A enorme valorização das empresas digitais reflete, em parte, o fato de serem donas do recurso mais importante do século XXI: dados, um resíduo digital das inúmeras redes e relações sociais, econômicas e culturais que se entrecruzam em nossas vidas. Na realidade, não seria inapropriado descrever a lógica que impulsiona o desenvolvimento desse setor como um "extrativismo de dados" - em um paralelo direto com o extrativismo de recursos naturais que mantém as atividades de empresas de energia e dos produtores de commodities em todo o mundo. A premissa-chave do extrativismo de dados é a de que os usuários são estoques de informações valiosas. As empresas de tecnologia, por sua vez, concebem formas inteligentes de nos fazer abdicar desses dados, ou, pelo menos, de compartilhá-los voluntariamente. (MOROSOV, 2018, p. 165)

No que diz respeito à educação, soluções em educação a distância (EAD) tiveram sua oportunidade de instalação definitiva - como já se nota:

Um mapeamento inédito, realizado por dois núcleos de pesquisa da Universidade Federal do Pará (UFPA) e pela Iniciativa Educação Aberta (Cátedra UNESCO de EaD sediada na Universidade de Brasília e Instituto Educadigital) revela que $65 \%$ das universidades públicas e secretarias estaduais de educação estão expostas ao chamado "capitalismo de vigilância". O início da exposição não data de 2020, no contexto da pandemia, mas se acirra nesse período em que as atividades presenciais estão suspensas pelas instituições de ensino. O serviço "eficiente, acessível e gratuito", das plataformas corporativas, paira como oferta mais que adequada em um momento em que há cortes de gastos generalizados nas universidades públicas e a perspectiva permanente de maximização dos lucros nas entidades privadas, para citar dois contextos em que tais serviços estão sendo incorporados. (LAVITS, 2020)

Para além da problemática do capitalismo de vigilância, o tema da potencialização em EAD estarrece pela tendência de maior fragilização do educador, cada vez mais dispensável e precarizado dentro do método de desvalorização dessa categoria. Não se 
trata de método à toa, vez que a mobilização democratizante que a escola pública pode oferecer é digna de um projeto para calar-Ihe a potência.

Paulo Freire menciona, em diálogo com Ira Shor, que o educador libertador nunca pode manipular ou abandonar o aluno à própria sorte, todavia possui um papel diretivo, trabalha os temas sem imposição, ainda que manifeste uma posição radicalmente democrática de um indivíduo que possui conteúdo a oferecer (FREIRE; SHOR, 1986, p. 203). Daí o receio de essas potencialidades se expressarem em tempos tão sedentos por transformações sistêmicas.

Quanto à tecnologia, não se pode deixar de mencionar as tensões que envolvem as atividades mediadas por plataformas como transporte individual de passageiros e entregas a domicílio, ambas reveladoras de mecanismos cruéis de expropriação do trabalho, aos quais o direito (que dá verniz a esse sistema econômico) trata de não equiparar a relações trabalhistas.

Durante o período de distanciamento social, muitos entregadores, por exemplo, estiveram expostos às agruras impostas pela atividade (em razão da necessidade de renda) dentro da dinâmica do capitalismo predatório, as quais foram agravadas pela falta de proteção no contexto da possibilidade de contágio. Mesmo assim, as plataformas de entrega em domicílio não deixaram de romantizar sua função como empresas que auxiliariam o distanciamento social através da manutenção das atividades, ainda que isso implicasse a exposição de trabalhadores e trabalhadoras sob ainda piores condições.

Todas essas menções remetem a conflitos eminentemente de classe, permeados por outros elementos de deterioração das relações sociais e exclusão. A ideia estereotipada de que a inovação tecnológica vai solucionar o cerne dos problemas sociais é uma falácia em sua essência, tendo em vista que o mundo digital tende a reproduzir as mesmas anomalias do mundo analógico; sem o tratamento de suas causas-raízes e sem o desvelamento dos interesses camuflados, não há avanço.

Valores sociais e valores tecnológicos possuem conflitos fundamentais e, em uma realidade de disparidades sociais e avanços tecnológicos pujantes, certamente atribuiu-se 
mais importância ao segundo - insubordinado aos valores sociais, que restam corroídos em muitas dimensões (LACEY, 1999, p. 114).

Por óbvio, a tecnologia demonstra a ampliação do entendimento científico (LACEY, 1999, p. 139), mas essa prerrogativa não garante que também demonstre a capacidade de compreensão dos valores sociais prioritários por si só. Ou seja, o fato de a humanidade estender seu entendimento para aparatos cada vez mais sofisticados não determina a alocação desses aparatos para a resolução de problemas humanos, aliás, apenas problematiza sua coexistência.

Por ser respaldada na hegemonia do sistema econômico, a ética da inovação possui limites bastante comprometidos no capitalismo, assim como sua democracia liberal. Antes de ser tarde, é importante reforçar que não se está em defesa da tecnofobia, mas em crítica ao entendimento de que existe um necessário benefício social em todo o ganho tecnológico e que há uma ética intrínseca a favor da tecnologia que dá respaldo à sua legitimidade.

Em um momento de cada vez maiores pleitos pela tecnologia, grandes empresas estadunidenses repensaram o lançamento de soluções em reconhecimento facial (HAMILTON, 2020), que possuem grande potencial na intensificação do racismo estrutural, por exemplo. Obviamente, dessas medidas não se deve esperar o anticapitalismo que o antirracismo demanda (HAIDER, 2018, p. 93), mas apenas a espera por regulação que traga segurança jurídica às novas soluções.

A inovação vem servindo aos interesses individuais de ganho com a mercantilização para descobertas que atraiam olhares admirados e que não servirão ao ganho social de forma obrigatória. Nessa lógica, o setor público torna-se o grande contratador de soluções privadas ${ }^{10}$, ao invés de investir em pesquisa capitaneada por universidades públicas ${ }^{11}$.

\footnotetext{
10 À guisa de exemplo, comenta-se das câmeras portáteis utilizadas por agentes de segurança pública em seus uniformes por supostamente (BRUCATO, 2015) diminuírem os índices de violência da abordagem policial, vez que proveriam maior transparência à atividade. Tais câmeras, não raramente, são oferecidas gratuitamente pela indústria de eletrônicos ao redor do mundo para testes pelos departamentos de polícia (CASSANO, 2017), que - acostumados à utilização dos aparelhos - acabam futuramente contratando as soluções ofertadas a título gratuito. Por meio de requerimentos mediados pela Lei de
} 
Como as interações técnicas carregam consigo valores cognitivos decorrentes de crenças e posições político-econômicas, é muito óbvia a maneira pela qual a máquina pública vai absorvendo a linguagem da iniciativa privada e o quanto esse cenário crítico clama por alternativas.

\section{Ecossocialismo como alternativa sistêmica mediada pelo Confederalismo}

\section{Democrático}

Como alternativa sistêmica, o ecossocialismo trata de promover uma resposta anticapitalista ao cenário distópico apresentado.

Se o problema é sistêmico, a solução tem de ser antissistêmica, isto é, anticapitalista. $O$ projeto ecossocialista consiste em associar 0 "vermelho" - a crítica marxista do capital e a alternativa socialista - com o "verde", a crítica ecológica do produtivismo. (QUERIDO, 2016, p. 29)

Trata-se de escolha por um modelo de crítica ao Estado liberal capitalista pelo prisma do materialismo histórico como método, tendo uma perspectiva ecológica de conjunto. A crise que permeia o capitalismo é uma crise civilizacional que exige mudanças radicais; não há coerência na distopia do “capitalismo limpo”, cujas escórias produtivistas não passam de manobra publicitária a contrapor uma corrente de pensamento e ação ecológicos que trazem consigo aquisições fundamentais do marxismo.

O ecossocialismo é prementemente calcado na predominância do ser pelo ter, através da mudança dos modelos de consumo, por um processo histórico permeado por

Acesso à Informação, esta pesquisa confirmou que a própria Polícia Militar de São Paulo chegou a receber, em doação operada pela multinacional Motorola durante o ano de 2020, tanto câmeras portáteis quanto a arquitetura de software envolvida no processamento das imagens coletadas pelos agentes públicos. Trata-se de relação cuja natureza jurídica dispensa o processo licitatório convencional brasileiro e possui um caráter bastante problemático sob vários pontos de vista, que incluem vigilantismo e um temerário processamento de dados pessoais.

11 Os vários cortes orçamentários operados em detrimento da pesquisa científica brasileira ganham confirmação pelo próprio atual ministro da Ciência, Tecnologia e Inovações (UOL, 2020) para 2021, mostrando o desprezo do governo federal pela pesquisa nacional. 
desafios educacionais (LOWY, 2014, p. 92). A catástrofe ambiental originada no capitalismo, que assola a humanidade e que deu ensejo à pandemia, só pode ser vencida através de um projeto ecossocialista, atrelado a alternativas sistêmicas como o ecofeminismo, o bem viver com influência dos povos tradicionais e o antirracismo.

O ecossocialismo tem como objetivo fornecer uma alternativa de civilização radical àquilo que Marx chamava de "o progresso destrutivo" do capitalismo. É uma escolha que propõe uma política econômica visando às necessidades sociais e ao equilíbrio ecológico e, portanto, fundada em critérios não-monetários e extra-econômicos. Os argumentos essenciais que o sustentam têm suas origens no movimento ecológico, assim como na crítica marxista à economia política. Essa síntese dialética - vislumbrada por um grande espectro de autores, de André Gorz a Elmar Altvater, James O’Connor, Joel Kovel e John Bellamy Foster - é ao mesmo tempo uma crítica à "ecologia de mercado" que se adapta ao sistema capitalista e ao "socialismo produtivista" que fica indiferente à questão dos limites da natureza. (LÖWY, 2009, p. 35)

Assim como já colocado, esse projeto, que contrapõe os limites impostos pelo lucro à frente da vida e mira a realidade mercantilizada para lhe traçar uma alternativa, pode buscar inspiração no Confederalismo Democrático que se instalou em Rojava a partir de $2012^{12}$. Trata-se de uma rica experiência que tem potencial para inspirar modelos alternativos; promoveu novas formas de organização popular de baixo para cima, reforçando que nenhuma mudança é operada sem luta política.

Como protetorado francês após o Acordo de Sykes-Picot ${ }^{13}$, a Síria era composta por aproximadamente um quinto de habitantes curdos - população com relativa autonomia durante o período colonial. Após a independência síria, as minorias étnicas foram perseguidas, dentre as quais o povo curdo; esse cenário apenas alterou-se na década de 80 do século XX, em razão da abertura do governo sírio ao Partido do

\footnotetext{
${ }^{12}$ Após o início dos levantes relacionados ao fenômeno da Primavera Árabe na Síria, os curdos se juntaram às manifestações e houve a organização de assembleias populares em Rojava - região declarada autônoma em 2012, compreendendo os cantões de Afrin, Kobane e Cizire (EGRET; ANDERSON, 2016, p. 22).

13 Trata-se de acordo secreto firmado em 1916 entre França e Reino Unido para definição da influência imperialista no Oriente Médio, considerando a queda do Império Otomano na Primeira Guerra Mundial.
} 
Trabalhadores do Curdistão - PKK ${ }^{14}$, como ferramenta política contra a Turquia (EGRET; ANDERSON, 2016, p.21).

Em razão de uma posterior ameaça turca de guerra contra a Síria, o PKK é forçado a sair do território sírio em 1998. Seu líder, Abdullah Öcalan, é preso em 1999. Na prisão, Öcalan é inspirado por ideias de Murray Bookchin; em razão da desilusão com formas estatais autoritárias e permeado pela ideia de participação social radical, propõe o Confederalismo Democrático (AYBOGA; FLACH; KNAPP, 2016), distanciando-se do marxismo-leninismo.

O Confederalismo Democrático retrata um modelo de resistência à modernidade capitalista, através de uma alternativa prática na qual tudo pertence e é deliberado pela comunidade; um modelo de substituição da exploração ecológica que marcava o regime sírio por uma sociedade de consciência ecológica e politizada.

Sem autogestão nas esferas econômicas, ética e política, não será possível transformar os homens de objetos passivos a sujeitos ativos. 0 espaço cívico (bairro, cidade) é o berço em que o homem se civiliza e civilizar é sinônimo de politizar, de transformar a "massa" em corpo político deliberativo, racional e ético. Formando e fazendo funcionar tais assembleias, os cidadãos formam-se a si mesmos, porque a política nada é se não for educativa e não promover a formação do caráter. (BOOKCHIN, 2019, p. 7)

A participação social em Rojava dá-se por meio de comunas que congregam representações de 30 a 400 moradias. Sendo as comunas a base do Confederalismo Democrático de Rojava, seus representantes formam o segundo nível deliberativo - fruto da reunião de 7 a 30 comunas. Há, ainda, o terceiro e o quarto níveis de deliberação, formados - respectivamente - pelos conselhos distritais (que representam cidades inteiras) e o conselho de distritos reunidos (demonstrando a cooperação entre os

\footnotetext{
${ }^{14}$ Fundado em 1978 por revolucionários turcos e curdos, dentre os quais esteve Abdullah Öcalan, era um partido de trabalhadores do Curdistão. Em sua origem defendia o marxismo-leninismo (EGRET; ANDERSON, 2016, p. 28).
} 
cantões). As instâncias de representação popular se organizam por meio de comissões temáticas (defesa, política, economia, ecologia, sociedade civil, sociedade livre, ideologia, justiça, mulheres).

Com relação ao modelo educacional que dá supedâneo à manutenção da revolução em Rojava, cada cantão possui um comitê educacional que administra a estrutura escolar da região (ESPINOSA; RONAN, 2019). Adicionalmente, um sistema de academias populares foi desenhado para disseminar formas de conhecimento que pudessem minar as estruturas existentes antes da revolução ${ }^{15}$, reiterando a democracia radical. No modelo curdo de educação popular observado em Rojava:

As academias [...] são centros de educação popular que possuíram um papel central na consumação de uma nova sociedade. Elas podem ser estabelecidas onde quer que os ativistas e movimentos sociais entenderem necessário e são orientadas para atender as necessidades básicas da população, estando abertas a todos, educando ativistas e todas as pessoas interessadas. Em Rojava [...] foram fundadas academias relativamente a autodefesa, mulheres, juventude, ecologia, [... ] economia, ideias e pensamentos livres, urbanização, direito e justiça, sociologia, história, linguagem, literatura, política e diplomacia. Ensinam de tudo, da língua local a filosofia, história e ciência. Até mesmo filósofos europeus - Descartes, Platão, Nietzsche e Marx - estão no currículo. As academias estão associadas aos conselhos populares [...] e são parte do Sistema de Autonomia Democrática. (AYBOGA; FLACH; KNAPP, 2016, p. 194)

Especialmente sobre essa proposta de um programa que contribui através da educação popular com a crítica a um modelo econômico que promove a releitura de fenômenos e espaços comuns em benefício de sua expansão e da amplitude da alienação como forma de legitimação, é ousada e necessária. Se a harmonização entre interesses opostos é - via de regra - uma tarefa improvável, principalmente se estamos falando de atores que se colocam em disparidade de forças, o objetivo da educação popular nesse contexto é trazer o conflito que há em temas que perpassam a vida do indivíduo em

\footnotetext{
15 Trata-se da construção de um movimento educativo independente, de academias que organizam espaços de discussão e seminários nas vizinhanças (SABIO, 2016).
} 
formação e que não são desnudados cotidianamente. Trata-se, ao fim e ao cabo, de instrumento para uma mudança de consciência que se oponha à conformação forjada pelo capitalismo.

Em virtude do modo pelo qual organizou a sua base tecnológica, a sociedade industrial contemporânea tende a tornar-se totalitária. Pois "totalitária" não é apenas uma coordenação política terrorista da sociedade, mas também uma coordenação técnico-econômica não terrorista que opera através das necessidades por interesses adquiridos. Impede, assim, o surgimento de uma oposição eficaz ao todo. (MARCUSE, 1973, p. 19)

O que Marcuse destaca é o caráter racional da irracionalidade, baseado em falsas necessidades doutrinadoras de indivíduos e na dominação dos dispositivos ideológicos e instituições sociais cujo fim é o lucro. Sendo assim, o espaço de contestação é prejudicado pela paralisia da crítica; integradas ao sistema, as classes não vislumbram a necessidade de transformação.

A dominação historicamente contínua dessa ideologia confere modos de pensar conformados; então, todo pensamento que nega o aparato social estabelecido ganha contornos especulativos ou utópicos. O convívio com o progresso cujo preço é a destruição evidencia construções sociais que justificam a repressão pela manipulação técnico-científica como forma de controle. Nesse sentido, a dinâmica do progresso técnico está permeada de conteúdo político e aponta para reprodução da dominação na qual toda a sociedade está envolta. Para pensar modos de transcender esse modelo, é imprescindível superar a própria razão que conflita com o interesse dos indivíduos a ela submetidos (MARCUSE, 2004, p. 42).

Por isso, e para a consecução da "vontade comum de desvencilhar-se, pela revolução, da ditadura do capital para construir uma sociedade desalienada, igualitária, liberada do jugo autoritário do Estado" (BESANCENOT; LÖWY, 2015, p. 188), propõe-se a elaboração de uma crítica lastreada no materialismo histórico para a junção de tendências 
emancipadoras que considere o ecossocialismo, bem como aprendizados da experiência de Rojava.

\section{Conclusão}

Em meio à percepção de que a crise econômico-social e política que assola a humanidade tem suas origens no capitalismo, surge a imperiosa atividade de posicionamento desobediente ao sistema:

A obediência é uma renúncia, ela sacrifica o si ético. E compreendemos então que, para encontrar um remédio para a tentação totalitária, para pensar as condições da resistência ao superpoder, Foucault e Arendt se deixam ambos convocar por Sócrates e por Kant: o Sócrates do exame dialético interminável, do cuidado de si; e o Kant da coragem da verdade e do pensamento que julga. É o pensamento pensante, o trabalho crítico que nos faz desobedecer. [...] Impedir-se de recitar receitas, de gaguejar fórmulas aprendidas, de aplicar soluções prontas, de receber evidências passivas - e principalmente confiar nas hesitações da consciência. Mais uma vez, princípio de responsabilidade indelegável: ninguém pode pensar em seu lugar, ninguém pode responder em seu lugar. (GROS, 2017, p. 182)

Trata-se de posicionamento que confronta a padronização do ser humano em objeto consumidor responsivo aos incentivos do mercado ou mesmo legitimador de movimentos contrários à vida; é o posicionamento de confronto da ética da inovação como pressuposto - a qual existe como premissa sem aliar-se às inquietações sociais, relegadas ao segundo plano.

Tendo sido dolorosamente alertados por um fenômeno pandêmico com origens no próprio jogo do capitalismo e entendendo que o emaranhado de relações sociais dele oriundo menospreza a gestão coletiva da coisa pública ${ }^{16}$, alternativas que rompam com a mercantilização de todas as instâncias da vida serão certamente propulsionadas por

\footnotetext{
${ }^{16}$ No caso brasileiro, quanto à área da saúde, por exemplo, tem destinação de recursos ao sistema único sempre questionada, gerando vácuo que se consolida em mercado à saúde suplementar.
} 
modelos de intensa participação popular nas tomadas de decisão, mediando um projeto contra-hegemônico.

Por fim, a intenção é que os temas debatidos mobilizem posicionamento crítico às utopias do capitalismo pandêmico como instigador de novas fronteiras e horizontes possíveis. As aberrações desveladas por esse período clamam por alternativas sistêmicas e qualquer solução deve ser mediada pela perspectiva de classe, para contraposição às novas formas de controle propostas pelo capitalismo.

Obviamente, a estrutura jurídica que sustenta o capitalismo permanecerá durante e após a pandemia, mas os estímulos por alternativas não podem esmorecer; as classes expropriadas devem manter o fôlego de sua indignação frente à exposição das agruras do sistema. Se há um novo tempo a ser construído, é o do pós-capitalismo e da democracia plena.

Transformar o ideal ético em combatividade frente às mazelas é convocação ao agir nas mínimas escolhas, aquelas que se relacionam com a indústria da carne, dos dados, das sementes geneticamente modificadas, das armas e tantas outras que estruturam seu arcabouço de valores contra a ética da desobediência - que se impõe frente às atrocidades políticas e ao conjunto de práticas em favor da manutenção de privilégios. Trata-se de um exercício individual que não se resume a um movimento unitário (BAUMAN, 2011, p. 12), já que a ética individual toma contornos públicos e direciona medidas políticas.

Como pontua Ellen Wood (1995, p. 293), "a lição que devemos ser obrigados a desenhar da nossa condição político-econômica é que um capitalismo humano, 'social', verdadeiramente democrático e equitativo é mais irrealisticamente utópico do que o socialismo".

\section{Referências}

ADORNO, Theodor. Capitalismo tardio ou sociedade industrial? In: COHN, Gabriel (org.). Theodor W. Adorno: sociologia. São Paulo: Ática, 1986. 
ANDREJEVIC, Mark; SELWYN, Neil. The new transparency: smartphones, data tracking, and COVID-19. Monash University, [Melbourne], 2020. Disponível em:

https://lens.monash.edu/2020/03/09/1379796/the-new-transparency-smartphones-datatracking-and-covid-19. Acesso em: 11 jan. 2021.

APPLE, Michael W. Para além da lógica do mercado: compreendendo e opondo-se ao neoliberalismo. Rio de Janeiro: GP\&A Editora, 2005.

AYBOGA, Asya; FLACH, Anja; KNAPP, Michael. Revolution in Rojava: democratic autonomy and women's liberation in Syrian Kurdistan. Londres: Pluto Press, 2016.

BAUMAN, Zygmunt. A ética é possível num mundo de consumidores? Rio de Janeiro: Editora Zahar, 2011.

BESANCENOT, Olivier; LÖWY, Michael. Afinidades revolucionárias: nossas estrelas vermelhas e negras: por uma solidariedade entre marxistas e libertários. São Paulo: Editora Unesp, 2015.

BRASIL. Medida Provisória n. ${ }^{\circ}$ 937, de 2 de abril de 2020. Abre crédito extraordinário, em favor do Ministério da Cidadania, no valor de R\$98.200.000.000,00, para os fins que especifica. Brasília: Presidência da República, 2020a. Disponível em: http://www.planalto.gov.br/ccivil_03/_ato2019-2022/2020/Mpv/mpv937.htm. Acesso em: 11 jan. 2021.

BRASIL. Medida Provisória n. ${ }^{\circ}$ 927, de 22 de março de 2020. Dispõe sobre as medidas trabalhistas para enfrentamento do estado de calamidade pública reconhecido pelo Decreto Legislativo $n^{\circ} 6$, de 20 de março de 2020, e da emergência de saúde pública de importância internacional decorrente do coronavírus (covid-19), e dá outras providências. Brasília: Presidência da República, 2020b. Disponível em: http://www.planalto.gov.br/ccivil_03/_Ato2019-2022/2020/Mpv/mpv927.htm. Acesso em: 11 jan. 2021.

BRUCATO, Ben. Policing made visible: mobile technologies and the importance of point of view. Surveillance \& Society, [North Carolina], v. 13, n. 3-4, p. 455-473, 2015. Disponível em: https://pdfs.semanticscholar.org/3ege/271aa505fc6952764ec29447c384202f24f2.pdf. Acesso em: 11 jan. 2021.

BOOKCHIN, Murray. Municipalismo libertário. Biblioteca Anarquista, [S.I.], 2019. Disponível em: https://bibliotecaanarquista.org/library/murray-bookchin-municipalismolibertario. Acesso em: 11 jan. 2021.

CASTELO, Graziela; VIEIRA, Priscila; PICANÇO, Monise (org.). A fome persiste nas comunidades ao lado do aumento de novas dimensões da violência: a descrença das 
decisões de flexibilização do distanciamento físico dificulta a contenção da pandemia.

Rede de Pesquisa Solidária, [São Paulo], n. 17, 2020. Disponível em:

https://redepesquisasolidaria.org/wp-

content/uploads/2020/07/boletimpps_17_24julho.pdf. Acesso em: 11 jan. 2021.

CASSANO, Jay. Police body camera company, Axon, is vacuuming in data, stoking privacy concerns. International Business Times, [S.I.], 16 ago. 2017. Disponível em:

https://www.ibtimes.com/political-capital/police-body-camera-company-axon-vacuumingdata-stoking-privacy-concerns-2579107. Acesso em: 11 jan. 2021.

COMUNA. Executivo da IV Internacional. IV Internacional sobre a pandemia Covid-19: Construamos a transição para o ecossocialismo agora! Comuna IV Internacional, [S.I.], 2020. Disponível em https://www.comunapsol.org/single-post/2020/04/17/Construamos-atransi\%C3\%A7\%C3\%A30-para-o-ecossocialismo-agora. Acesso em: 11 jan. 2021.

CRARY, Jonathan. 24/7 capitalismo tardio e os fins do sono. São Paulo: Editora Ubu, 2016.

DIAS, Tatiana. Vigiar e Lucrar. Nós identificamos dois clientes dos dados de localização 'anônimos' vendidos pela Vivo. The Intercept, [Rio de Janeiro], 2020. Disponível em: https://theintercept.com/2020/04/13/vivo-venda-localizacao-anonima/. Acesso em: 11 jan. 2021.

DUFOUR, Dany-Robert. A arte de reduzir as cabeças: sobre a nova servidão na sociedade ultraliberal. Rio de Janeiro: Companhia de Freud, 2005.

DUPAS, Gilberto. O Mito do progresso ou progresso como ideologia. São Paulo: Editora Unesp, 2012.

EGRET, Elisa; ANDERSON, Tom. Struggles for autonomy in Kurdistan \& corporate complicity in the repression of social movements in Rojava \& Bakur. London: Corporate Watch, 2016.

ESPINOSA, Elise Boyle; RONAN, Adam. Education in Rojava: propagation of the Democratic Nation ideology and its implications for governance in Northern Syria. Dissertation (Master of Science in Global Development) - University of Copenhagen, Copenhagen. 2019.

ESTEVE, Esther Vivas. O negócio da comida: quem controla nossa alimentação. São Paulo: Editora Expressão Popular, 2017.

FOSTER, John Bellamy. Marx's theory of metabolic rift: classical foundations for environmental sociology. American Journal of Sociology, [Chicago], v. 105, n. 2, p. 366405, 1999. 
FREIRE, Paulo; SHOR, Ira. Medo e ousadia: o cotidiano do professor. Rio de Janeiro: Paz e Terra, 1986.

GROS, Frédéric. Desobedecer. São Paulo: Ubu Editora, 2017.

GUIMARÃES JÚNIOR, Djalma Silva et al. Efeitos da pandemia do COVID-19 na transformação digital de pequenos negócios. Revista de Engenharia e Pesquisa Aplicada, Recife, v.5, n. 4, p. 1-10, 2020.

HAIDER, Asad. Mistaken identity. Londres: Verso, 2018.

HAMILTON, Isobel Asher. Outrage over police brutality has finally convinced Amazon, Microsoft, and IBM to rule out selling facial recognition tech to law enforcement: here's what's going on. Business Insider, [New York], 2020. Disponível em:

https://www.businessinsider.com/amazon-microsoft-ibm-halt-selling-facial-recognition-topolice-2020-6\#ibm-1. Acesso em: 11 jan. 2021.

KONDER, Leandro. Introdução ao Fascismo. São Paulo: Expressão Popular, 2009.

LACEY, Hugh. Is science value free?: values and scientific understanding. London: Routledge, 1999.

LAVITS - Rede Latino-Americana De Estudos Sobre Vigilância, Tecnologia E Sociedade. No tempo da catástrofe, capitalismo de vigilância avança sobre a educação no Brasil. [S.I.], 2020. Disponível em: http://lavits.org/no-tempo-da-catastrofe-capitalismo-de-vigilanciaavanca-sobre-a-educacao-no-brasil/?lang=pt. Acesso em: 11 jan. 2021.

LEITE, Rubens José; BECHHAUSER, Elisa; BROETTO, Valeriana. Crise ecológica e coronavírus: o repensar para a ecologização do direito. [Florianópolis], 2020. Disponível em:

https://www.researchgate.net/publication/340680979_CRISE_ECOLOGICA_E_CORONAVI RUS_O_REPENSAR_PARA_A_ECOLOGIZACAO_DO_DIREITO. Acesso em: 11 jan. 2021.

LÖWY, Michael. O que é ecossocialismo? São Paulo: Editora Cortez, 2014.

LÖWY, Michael. Ecossocialismo e planejamento democrático. Crítica Marxista, Campinas, n. 28, p. 35-50, 2009. Disponível em:

https://www.ifch.unicamp.br/criticamarxista/arquivos_biblioteca/artig0164Artigo3.pdf. Acesso em: 11 jan. 2021.

MARCUSE, Herbert. A ideologia da sociedade industrial. Rio de Janeiro: Zahar Editores, 1973. 
MARCUSE, Herbert. Tecnologia, guerra e fascismo. Londres: Taylor \& Francis e-Library, 2004.

MASCARO, Alysson Leandro. Estado e forma política. Rio de Janeiro: Editora Boitempo, 2013.

MOROSOV, Evgeny. Big tech: a ascensão dos dados e a morte da política. São Paulo: Ubu Editora, 2018.

OLIVEIRA, Francisco de et al. O ornitorrinco. São Paulo: Boitempo, 2003.

PETHERICK, Anna; GOLDZMIDT, Rafael; KIRA, Beatriz; BARBERIA, Lorena. As medidas governamentais adotadas em resposta ao COVID-19 no Brasil atendem aos critérios da OMS para flexibilização de restrições? Universidade de Oxford, [S.I.], 2020. Disponível em: https://www.bsg.ox.ac.uk/sites/default/files/2020-06/BSG-WP-2020-033-PT.pdf. Acesso em: 11 jan. 2021.

QUERIDO, Fabio Mascaro. Michael Lowy: marxismo e crítica da modernidade. São Paulo: Editora Boitempo, 2016.

ROSO, Jayme Vita. Anorexia da ética e outros escritos. Belo Horizonte: Armazém de Ideias, 2004.

SABIO, De Oso. Rojava: Una alternativa al imperialismo, nacionalismo e islamismo en el Medio Oriente. [S.I.: s.n], 2016.

SERRES, Michel. A Guerra Mundial. Rio de Janeiro: Bertrand Brasil, 2011.

SHARMA, Tanusree; BASHIR, Masooda. Use of apps in the COVID-19 response and the loss of privacy protection. Nat Med, 2020. Disponível em: https://doi.org/10.1038/s41591-0200928-y. Acesso em: 11 jan. 2021.

UCHÔA, Karina. Burnout e assédio moral continuam em tempos de pandemia. Veja Saúde, [São Paulo], 2020. Disponível em: https://saude.abril.com.br/blog/com-apalavra/burnout-e-assedio-moral-continuam-em-tempos-de-pandemia/. Acesso em: 11 jan. 2021.

UOL - Universo Online. Marcos Pontes diz que órgãos de pesquisa devem sofrer cortes no ano que vem. São Paulo, 2020. Disponível em:

https://educacao.uol.com.br/noticias/2020/08/17/marcos-pontes-cortes-pesquisas.htm. Acesso em: 11 jan. 2021. 
VIANA, Nildo. Sobre a relação capitalismo-pandemia. A Terra é redonda, [S.I.], 2020.

Disponível em: https://aterraeredonda.com.br/sobre-a-relacao-capitalismo-pandemia/. Acesso em: 11 jan. 2021.

WOOD, Ellen Meiksins. Democracy against capitalism: renewing historical materialism. Cambridge: Cambridge University Press, 1995.

Recebido em: 30/06/2020 Aprovado em: 18/11/2020

Universidade do Estado de Santa Catarina - UDESC Centro de Ciências Humanas e da Educação - FAED

Volume 21 - Número 47 - Ano 2020 revistapercursos@gmail.com 